\title{
Efficacy of Maximun Anchoring Using Transpalanance and Double ATP in Cases Requiring First Superior Premolar Extractions: A Comparative Analysis
}

\section{Eficacia del anclaje máximo usando transpalanance y doble ATP en casos de extracciones de primeros premolares superiores: Análisis Comparativo}

\author{
William Ubilla-Mazzini DDS, Esp; Tanya Moreira-Campuzano DDS, Esp. 1; \\ Fátima Mazzini-Torres DDS, MSc² \\ 1. Dentist. Specialist in Orthodontics. Teacher at the University of Guayaquil, Ecuador.
}

2. Doctor in Dentistry. Magister in Clinical and Epidemiological Research. Teacher at the University of Guayaquil, Ecuador.

Correspondence to: Dr. William Ubilla-Mazzini - william.ubillam@ug.edu.ec

Received: 8-VI-2019

Accepted: 8-VII-2019

Published Online First: 16-VII-2019

DOI: $10.15517 / / J D S .2019 .38364$

\section{ABSTRACT}

Introduction: Space maintainers play an important role in orthodontic treatments involving premolar extractions, especially in cases with bad occlusion and marked crowding. The orthodontist must know several options of anchoring and choose the best method that would fulfill the treatment objectives for that patient. Objective: To compare the effects of maximum anchors like the double transpalatal arch (double ATP) and the transpalatal arch and Nance button combination (transpalanance) as space maintainers during cuspids retraction in patients undergoing upper bicuspid extractions. Methods: A universe of 100 patients, aged 14-25 years, was selected from among the patients presenting to the Orthodontics Specialty Clinic of the posgraduate School Dr. José Apolo Pineda, Pilot School of Dentistry, University of Guayaquil during the years of 2017 and 2018. Totally, 26 patients were recruited, of whom 13 were placed on transpalanance and the other 13 on double ATP, prior to the extraction of their first upper bicuspid. Post-extraction spaces were measured and compared with post-retraction spaces of upper cuspids. Results: With an average of 4-5 mm, transpalanance maintained the greatest amount of space at the end of canine retraction. It is expected that the results obtained in this study will be useful to orthodontists, providing them with information regarding the most effective space maintainers for treatments with extractions. Conclusion: The maximum anchor that showed the greatest efficacy was transpalanance since it maintained a greater amount of space during its time of use.

\section{KEYWORDS}

Cuspids; First bicuspids; Space maintenance. 


\section{RESUMEN}

Los mantenedores de espacio desempeñan un papel importante en los tratamientos de ortodoncia que incluyen extracciones premolares, especialmente en casos de oclusión grave y aglomeración marcada. El ortodoncista debe conocer varias opciones de anclaje y elegir el mejor método que cumpla con los objetivos de tratamiento para ese paciente. Objetivo: comparar los efectos de los anclajes máximos como el arco transpalatino doble (ATP doble) y el arco transpalatino y la combinación del botón de Nance (transpalanance) como mantenedores de espacio durante la retracción de los cúspides en pacientes sometidos a extracciones de premolares superiores. Métodos: Se seleccionó un universo de 100 pacientes, de 14 a 25 años, entre los pacientes que acudieron a la Clínica de Ortodoncia de la Escuela de Posgrado de la Facultad Piloto de Odontología, Universidad de Guayaquil durante los años de 2017 y 2018. En total, se reclutaron 26 pacientes, de los cuales 13 fueron colocados en transpalanance y los otros 13 en doble ATP, antes de la extracción de su primer premolar superior. Los espacios posteriores a la extracción se midieron y compararon con los espacios posteriores a la retracción de los caninos superiores. Resultados: Con un promedio de 4 a $5 \mathrm{~mm}$, el transpalanance mantuvo la mayor cantidad de espacio al final de la retracción de caninos. Se espera que los resultados obtenidos en este estudio sean útiles para los ortodoncistas, proporcionándoles información sobre los mantenedores de espacio más efectivos para los tratamientos con extracciones. Conclusión: el ancla máxima que mostró la mayor eficacia fue la transpalanidad, ya que mantuvo una mayor cantidad de espacio durante su tiempo de uso.

\section{PALABRAS CLAVE}

Caninos; Primeros premolares; Mantenedor de Espacio.

\section{INTRODUCTION}

Class II malocclusion (Angle's classification of malocclusion) is a frequently found type of malocclusioncharacterized by greater growth of the maxilla than of the mandible resulting in labial incompetence and high proclined incisors; predisposing factors include oral habits such as finger-sucking or lower lip-sucking (1). The use of attachments on the palate becomes necessary in these cases. This has been reported by several authors as a successful means of maximally anchoring orthodontic treatments.

An orthodontic anchor is a device used to resist the movement of a tooth or group of teeth before the application of a force (2). The appliances used for anchoring are diverse and can be removable or fixed (3).
In early orthodontics, teeth were used to achieve control of the anchor, but there were limitations to this technique. To overcome these limitations, various forms of anchoring were explored, such as vestibular screens, extraoral traction, transpalatal bars, and lingual arches. Other traditional anchor systems used extraoral elements such as extraoral arches, or intraoral devices such as the Nance button; but they may not always be stable as they depend on the patients' cooperation to a large extent (4).

The first step in the evaluation of a patient for the use of space maintainers is to confirm the presence of the permanent successor using a panoramic radiograph. If there is agenesis of the successor, it should be decided whether the space will be maintained until a definitive substitute is placed. Once the occlusion has stabilized or if the 
space is allowed to close, orthodontist intervention is indicated, as these cases will generally require subsequent tooth alignment. The second premolars are those that are most often congenitally absent or sometimes, they are formed much later than normal; thus, at 10 years of age, an $x$-ray can reveal a developing premolar that was absent 2 years prior. These late developing second premolars often show variations in shape and size.

The treatment of Class II malocclusion involves the removal of the upper premolars (but not the lower premolars) unless the lower anterior anchor is carefully controlled. If extractions are performed in the lower arch without adequate anchoring of the incisor front, the lower incisors can be retracted, thus increasing the need for upper incisors and upper lip retraction (5).

The purpose of anchoring devices is to maintain the perimeter and transverse width of the arches and serve as a support to correct individual rotations. They also serve as an anteroposterior support to correct asymmetries, help maintain the level of the occlusal plane, increase resistance to reaction units, and prevent tilt and rotation of the molars in mechanical closure, in addition to maintaining intermolar distance (6).

Orthodontic treatment has several stages. First, we have alignment and leveling; this can generate a lot of confusion as it involves 2 different phases. The second stage consists of closing the spaces left by the extractions of the permanent teeth. The third and final stage is the finalization and mechanical retention phase, which should have a minimum follow-up of 1 year (7).

During upper first premolar extraction, the conservation of space is crucial to prevent the physiological mesialization of dental pieces; this is one of the main objectives of orthodontic treatment as it improves the patient's profile, corrects dental inclinations, achieves canine class I etc. That is why in this research work, we compared the efficacy of 2 maximum anchors; this would provide valuable information to orthodontists while finalizing treatment plans.
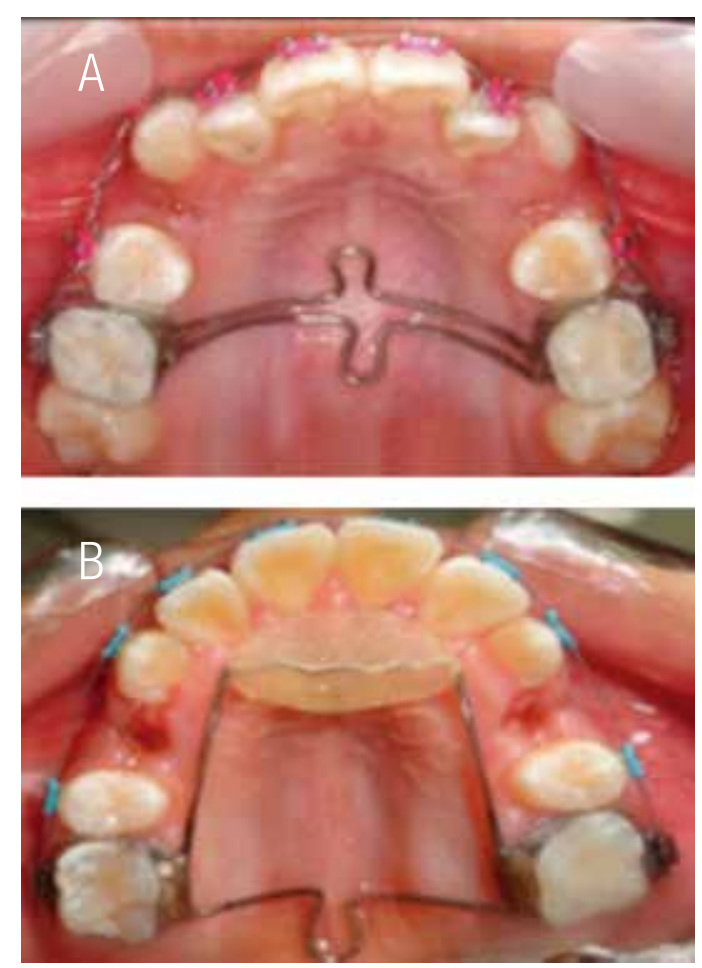

Figure 1. A. Double transpalatal arch (double ATP); B.Transpalatal arch and Nance button combination (transpalanance).

Bibliographical, descriptive, quantitative, and qualitative methods were used to verify the hypothesis. Measurements were made before and after upper canine retraction, which were then used to quantify the efficacy of the space maintainer or anchorage.

This will provide help when planning orthodontic treatment, which ultimately aims to achieve a harmonious occlusion and good dental aesthetics.

Professionals face many issues either due to lack of knowledge or poor application of orthodontic mechanics. The purpose of this investigation was to determine the efficacy of the double transpalatal 
arch (double ATP) and the transpalatal arch and Nance button combination (transpalanance) as space maintainers during superior canine retraction.

The objective of this study is to compare the effects of maximum anchors like the double transpalatal arch (double ATP), Figure 1. A and the transpalatal arch and Nance button combination (transpalanance) Figure 1. B as space maintainers during cuspids retraction in patients undergoing upper bicuspids extractions.

\section{MATERIALS AND METHODS}

A universe of 100 patients (aged 14-25 years) whose diagnoses indicated extraction of the upper first premolars was included in the study. Of these, 26 patients needed the use of space maintainers or maximum anchors in addition to the extractions; 13 of them were placed on transpalanance (Figure 2) and 13 on double ATP (Figure 3). The inclusion criteria were as follows: Class II skeletal patients, requiring extraction of first premolars, aged 14-25 years; and the exclusion criteria were as follows: Class I or III skeletal patients, requiring extractions of upper second premolars, or ages $<14$ years or $>25$ years. Signed informed consent were obtained from all the patients to publish their cases. The present study has been approved for publication by the Research Council and the Ethics Committee of the Odontology Pilot School of the University of Guayaquil, with resolution CIFP0-UG-59-2019.

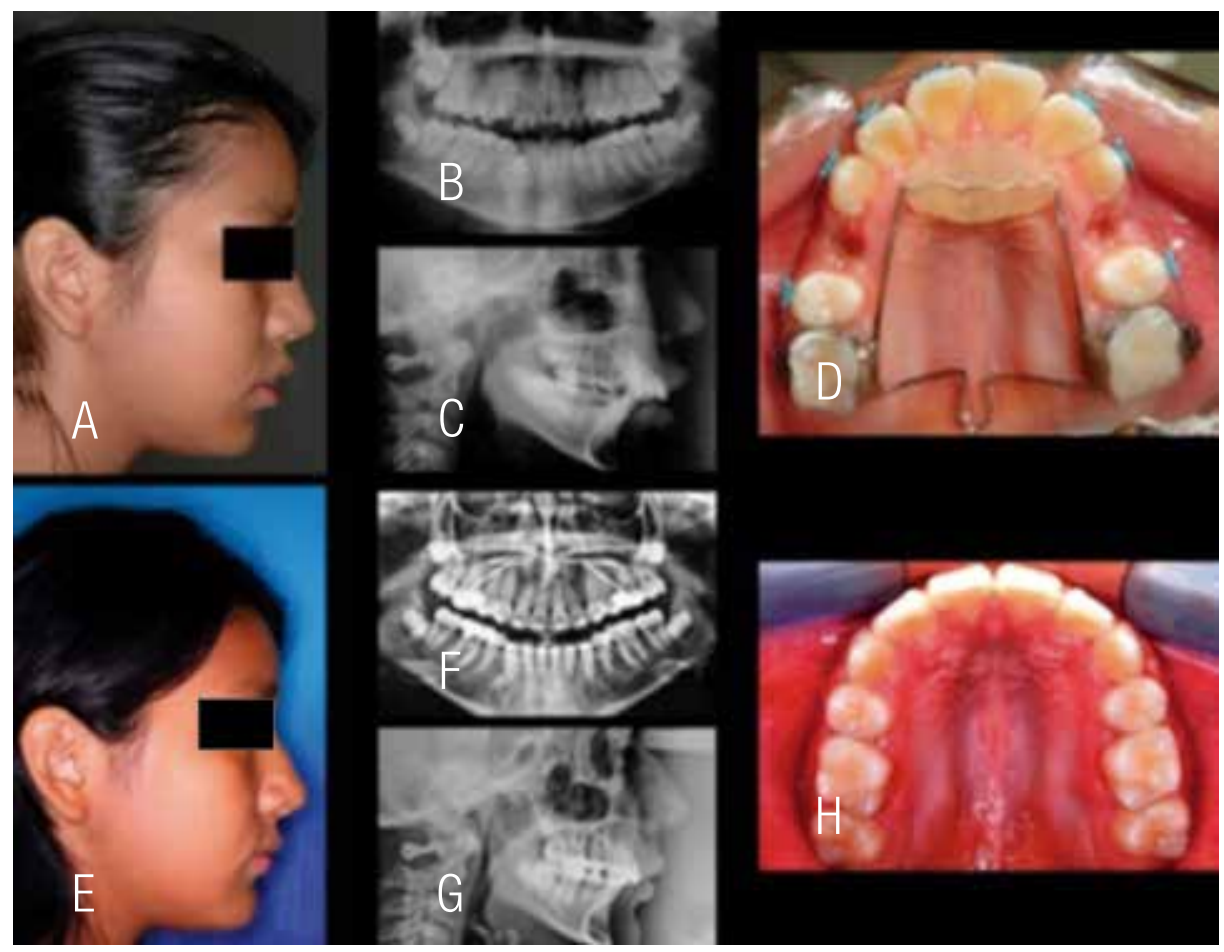

Figure 2. Treatment using transpalatal arch and Nance button combination (transpalanance): A. Initial profile view, B. Rx Initial overview, C. Initial cephalometric Rx, D. Initial palatine view, E. Final profile view, F. Rx Final panorama, G. Final cephalometric Rx, and H. Final palatine view. 


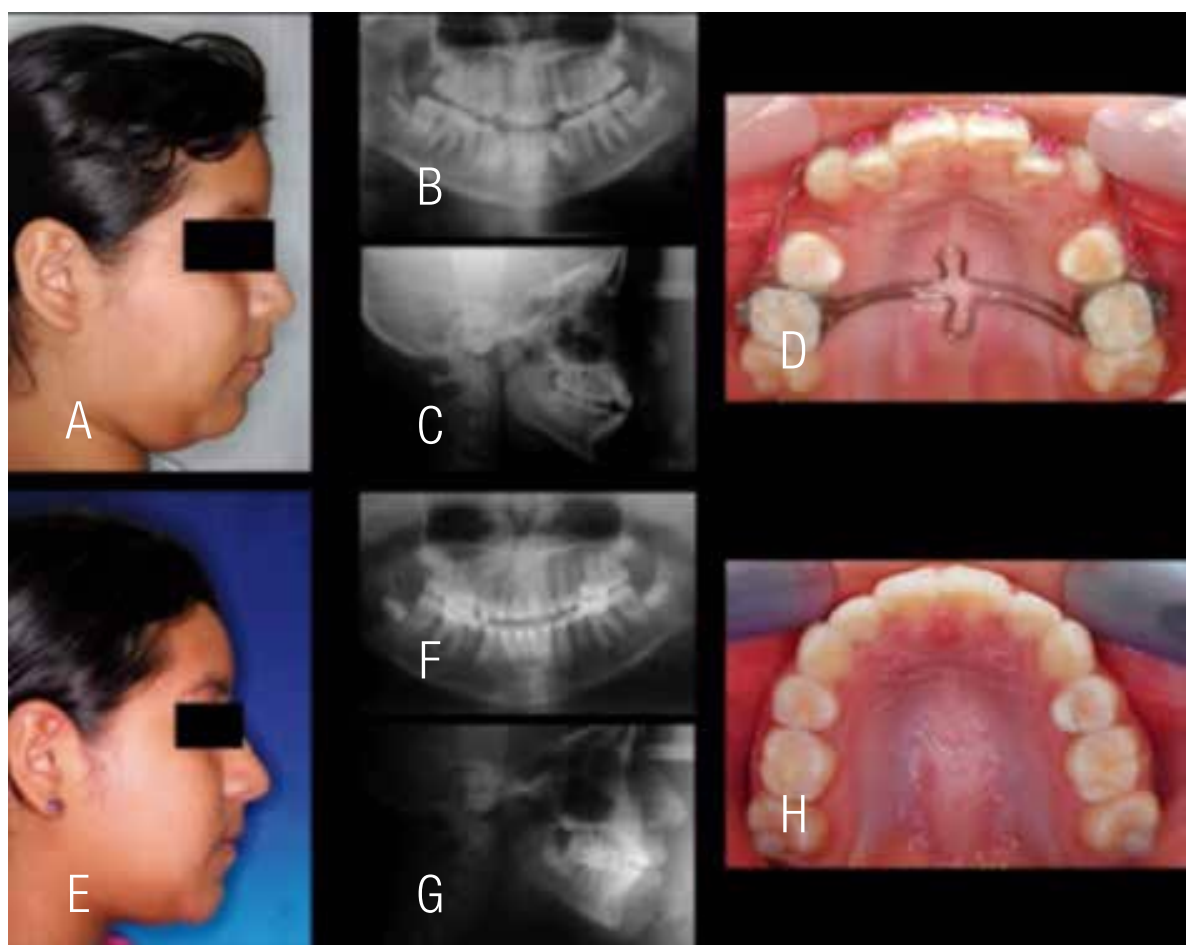

Figure 3. Treatment using double transpalatal arch (double ATP): A. Initial profile view, B. Rx Initial overview, C. Initial cephalometric Rx, D. Initial palatine view, E. Final profile view, F. Rx Final panorama, G. Final cephalometric Rx, and H. Final palatine view.

Millimeter rulers, study models, photographs before and after upper canine retraction, computers, books, and scientific articles were used for measurements and analysis. Likewise, we counted on the cooperation of patients from the Orthodontics Specialty Clinic of the Graduate School Dr. José Apolo Pineda, Pilot School of Dentistry, University of Guayaquil (during the years 2017 and 2018), as well as the students, tutors and staff of the same.

Measurements were made of the spaces left after the upper bicuspids extractions, between the cuspids and $2 \mathrm{~d}$ bicuspids. The space maintainers or anchors mentioned above were placed, and measurement of the space between the cuspids and $2 \mathrm{~d}$ incisors, were repeated once the upper cuspids retraction was finished.

This is a descriptive study, and the results are shown as tables and presentations. This is to compare the efficacy of double ATP and transpalanance, as space maintainers during upper canine retraction, establish accurate criteria for their use, and create a basis for future research.

\section{RESULTS}

The maximum duration of canine retraction was 3-5 months in 8 patients (with both maintainers), $>5$ months in 15 patients (9 with double ATP and 6 with transpalanance), and 1-3 months in 3 patients (using transpalanance). This was because transpalanance has a stricter control, and therefore allows for better mechanical canine retraction (Figure 4A).

It is observed that the maximum duration of use for transpalanance, was relatively less than that for double ATP. This is because once canine retraction was achieved, the Nance button was removed and only the transpalatal arch was maintained in case of transpalanance, while the 
double ATP remained intact in most cases until the anterior segment retraction was performed. Transpalanance offers a greater control of the width, which consequently allows it to be used for less time than the double ATP (Figure 4B).

We also noticed that both maintainers provided an average space conservation of 3-4 $\mathrm{mm}$, taking into account the loss of space due to the correct alignment of the anterior teeth and the mesialization of the posterior sector. However, transpalanance was able to maintain a width of $>5$ $\mathrm{mm}$ in 5 patients, unlike double ATP which achieved this value only in 1 patient. This is because of the double support provided by the Nance button (palatal mucosa) together with the transpalatal arch (first molars), make transpalanance the more effective option for space conservation in upper canine retraction (Figure 4C).

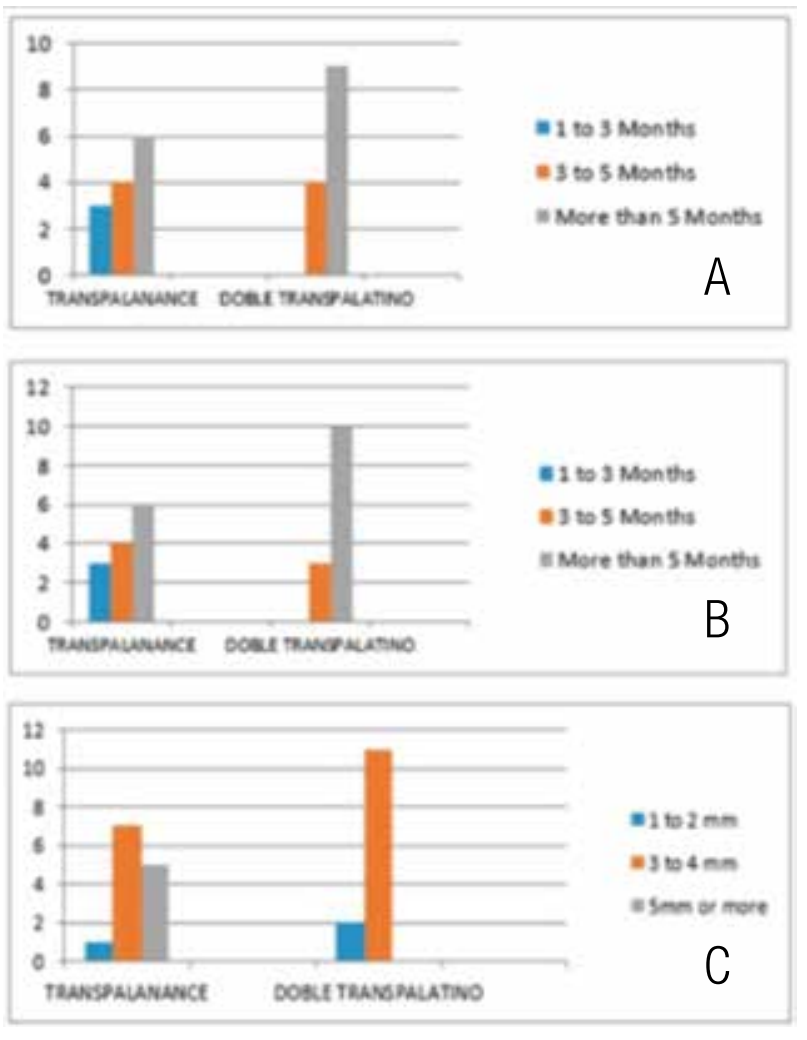

Figure 4. A. Duration of canine retraction; B. Maximum duration of use of anchors; C. Space Conservation.

\section{DISCUSSION}

In this study, both maintainers provided an average space conservation of 3-4 $\mathrm{mm}$, taking into account the loss of space due to the correct alignment of the anterior teeth and the mesialization of the posterior sector. However, transpalanance was able to maintain a width of $>5 \mathrm{~mm}$ in 5 patients, unlike double ATP which achieved this value only in 1 patient.

Existing literature shows that maximum or severe anchorage provides $70 \%$ anchorage, and allows a mesial migration of molars up to $30 \%$ of the premolar extraction space. According to Nanda, this category is called Anchorage A: critical maintenance of the position of the anterior teeth, where $\geq 75 \%$ of the retraction space is needed for its retraction. Examples of this type include Arco RN (Rodríguez-Natera), transpalanance, and the combination of an extraoral arch with transpalatal $\operatorname{arch}(7)$.

During this investigation, it was possible to confirm that the loss of space was $30 \%$, since both type of anchorage conserved 3-4 mm after the completion of canine retraction, which allowed the orthodontist more space for the retraction of the anterior segment.

Maximum anchorage is used when there is severe crowding or when significant facial change is needed, for example class II division I or biprotrusive patients. In 1984, Dr. Celtin showed that anchors not only served to maintain space, but also helped avoid extrusion of the molars, even favoring their intrusion (8).

In this study it was possible to determine that transpalanance provided greater anchoring than double ATP, since it has double support or anchoring (both at the level of the molars with the transpalatal arch and at the level of the palatal mucosa with 
the Nance button), thereby better conserving the upper premolar extraction space.

At the start of canine retraction, it is important to have completed the previous stages of alignment and leveling of the dental pieces, in order to prevent unwanted movements of the canines and the resultant delays in the treatment plan. (9) The ideal bows for canine retraction are $0.016 \times 0.016$ or $0.016 \times 0.022$ caliber stainless steel, in combination with elastic chains or springs made of nickel, titanium, or stainless steel (10).

Different studies have described the advantages and disadvantages of the use of anchors in orthodontic treatment. In this research work, it can be noted that both the anchors, transpalanance and double ATP, conserved an average of 3-4 mm in cases where upper premolar extraction was performed. In addition, these anchors represent an important alternative for those patients who cannot afford mini orthodontic implants.

Several authors agree on the use of the transpalatal arch and Nance button combination as the maximum anchorage of choice to maintain the position of the first upper molars. Others mention that maximum anchorage also minimizes unwanted secondary movements and creates unidirectional movements (11). This correlates well with the findings of this study, since it was possible to achieve the highest degree of space conservation in cases with first upper premolar extraction using transpalanance.

The transpalatal arch is used to prevent the mesiodistal rotation of the molars in mechanical closing of spaces that involve retraction or protraction en masse (12), while the Nance button reinforces the anchor of the upper molars, to rotate the molars and expand the maxilla. In this study, both transpalanance and double ATP, allowed a greater control of the anchorage and helped to better correct the dental discrepancies.

It is difficult to achieve anchoring control in orthodontic treatments involving first premolar extractions, where it is necessary to maintain the position of the first molars. However, the use of maximum anchors such as transpalanance, seem to be effective in controlling the anchorage during the anterior segment retraction (canines and/or anterior 4 en masse) (13). During the realization of this type of study it is very important to have the collaboration of the patient in the fulfillment of his appointments, since this will allow to have a greater control of the maintenance of the spaces and of the correct use of the orthodontic biomechanics.

\section{CONCLUSION}

Transpalanance is a maximum anchor and is a more effective space maintainer than the double ATP. It preserves the spaces left by premolar extractions in a greater percentage of patients than double ATP, thus helping in the final correction of dental discrepancies. Transpalanance is one of the best anteroposterior and transverse anchorage systems for the maxilla. Its mechanical function is simple and is used to avoid the mesialization of the molars in mechanics of closure of spaces involving retractions or protractions en masse. The present investigation provides important data to the Orthodontists when choosing a maximum anchor that allows them to conserve the greatest amount of space during the closing phase of spaces, and thus achieve the correction of the facial asymmetries that the patient presents. 


\section{REFERENCES}

1. Echandia, Giovanni Oberti, et al. Treatment alternative for the distalization of upper molars with a transpalatine bar anchored to a mini-implant. CES Journal Odontology, 2010, vol. 23, no 2, p. 73-78.

2. Rodriguez, E. 1,001 Tips in Orthodontics and its Secrets. Mexico: Amolca. 2007.

3. Pérez García, Lizandro Michel, et al. Use of mini implant in patient with asymmetric anchorage requirement. Presentation of case. Medical Gazette of Espirituana, 2013, vol. 15 , no 3, p. 306-311.

4. ROMERO, M., et al. Loss of anchoring in patients treated with extraction of upper first premolars. Latin American Journal of Orthodontics and Pediatric Dentistry, 2007.

5. Echarri, P. Orthodontic treatment with extractions. Madrid-Spain: Ripano. 2010.

6. Rey, Diego; Oberti, Giovanni; Sierra, Angela. Removal of the first permanent molar as an alternative in the treatment of orthodontics (Extractions of first permanent molars as a choice of the orthodontic treatment). CES Dentistry, 2012, vol. 25, no 1, p. 44-51.

7. Uribe, G. Orthodontics Theory and Clinic, 2nd Edition. Medellin-Colombia: CIBCorporacion para Investigación Biologica. 2010.

8. Viglianisi, A. (October 2010). Effects of lingual arch used as space maintainer on mandibular arch dimension: A systematic review. American Journal of Orthodontics and Dentofacial Orthopedics, Volume 138, Issue 4.

9. Uribe, F.; Nanda, R. Treatment of Class II, Division 2 malocclusion in adults: biomechanical considerations. Journal of Clinical Orthodontics, 2003, vol. 37, no 11, p. 599-606.

10. Sayin, Seher, et al. Rapid canine distalization using distraction of the periodontal ligament: a preliminary clinical validation of the original technique. The Angle Orthodontist, 2004, vol. 74, no 3, p. 304-315.

11. Ordóñez, Cd Francisco Shamed Méndez, et al. Corrective Treatment of Bimaxillary Class I Moderate Dentoalveolar Protrusion: BimaxillaryDentoalveolarDistalization with Mini Implants. Mexican Journal of Orthodontics, 2018, vol. 6, no 2, p. 98-111.

12. Burstone C.J. Precision adjustement of the transpalatal lingual arc: computer arch form determination. Am.J.Orthod: 79: 115133, 1981.

13. Romero, M. Gurrola, B. Mendoza, J. Casasa, A. 2007, Lost of anchoring in patients treated with extraction of upper first premolars. Latin American Journal of Orthodontics and Odontopediatrics "Ortodoncia.ws electronic edition October 2007. Available at: www. ortodoncia.ws. 